\title{
Case Study in International Cooperation: Cuba's Molecular Immunology Center and Roswell Park Cancer Institute
}

\author{
Rachel Evans MS, Mary Reid MSPH PhD, Brahm Segal MD, Scott I. Abrams PhD, Kelvin Lee MD
}

\begin{abstract}
In 1961, the USA severed diplomatic relations with Cuba, and in 1962 an embargo was imposed on trade and financial relations with that country. It was not until five decades later that the USA and Cuba would reestablish relations. This opened the way for the New York State Trade Mission to Cuba in April 2015, during which Cuba's Molecular Immunology Center and Buffalo, New York's Roswell Park Cancer Institute signed a formal agreement that would set in motion biotechnology research collaboration to address one of the most important causes of death in both countries. Significant research from Cuba led to this groundbreaking collaboration. The purpose of this paper is to discuss the development of this cooperation, from the Molecular Immunology Center's initial investigations, through the opening of a phase I clinical trial at Roswell Park Cancer Institute with therapies developed at the Center. This cooperation was responsible
\end{abstract}

for the first clinical trial for CIMAvax-EGF involving advanced-stage non-small cell lung cancer patients in the USA. A license was also approved by the US Department of the Treasury's Office of Foreign Assets Control authorizing a commercial partnership for development of biotechnology products, combining the cancer research efforts of both institutions. This unusual collaboration between Cuba and the USA - the US economic embargo and travel restrictions not withstanding -opens good prospects for expanded medical research between the two countries. While political and logistical challenges remain, the shared mission and dedication of these Cuban and US scientists points the way towards relationships that can lead to development, testing, approval and use of promising new therapies for cancer patients.

KEYWORDS Biotechnology, clinical trials, cancer vaccines, cancer immunotherapy, non-small cell lung cancer, NSCLC, Cuba, USA

\section{INTRODUCTION}

Before 1959, the USA and Cuba were active trading partners. In 1961, the US government severed diplomatic relations with Cuba, and a year later declared an economic, trade and financial embargo on the country. It was not until December 17, 2014, that Presidents Barack Obama and Raúl Castro agreed to resume bilateral relations and to reopen embassies in their respective capitals.[1] Years prior to the Obama presidency, the American Association for the Advancement of Science, the New America Foundation and others had supported scientists' travel between Cuba and the USA. Unfortunately, this support was not enough to thaw relations between the two countries.[2]

Renewed relations, however, opened opportunities for growth along multiple pathways for joint efforts in biomedical research and other fields.[3] In April 2015, New York Governor Andrew Cuomo led a state trade mission to Cuba, during which a formal agreement was signed between the Molecular Immunology Center (CIM) in Havana and Buffalo's Roswell Park Cancer Institutes (RPCI), to further develop CIM's cancer vaccines.[4] The formal agreement, based in several years of conversations between the two institutions, paved the way for new medical collaborations with potential benefits for people in both countries and abroad.

IMPORTANCE This collaboration is a unique opportunity to share resources and enhance access to knowledge and technology for both Cuban and US scientists and institutions. Such cooperation can bring forward new, effective therapies derived from biotechnology to benefit cancer patients in the USA, Cuba and internationally.
However, as bilateral contacts between Cuban and US professionals move ahead, the embargo and the travel restrictions remain in place. US regulations permit only certain activities under general or specific license from the US Department of the Treasury's Office of Foreign Assets Control (OFAC), as well as certain categories of US travel to Cuba. [5] Travel by Cubans to the USA has recently become more difficult, due to restrictions imposed by the new administration in Washington,[6] and it remains to be seen what effects these might have on joint scientific and medical research efforts.

\section{DEVELOPMENT OF CUBA'S HEALTH SYSTEM, BIOTECHNOLOGY AND CLINICAL TRIAL CAPABILITIES}

Prior to 1959, Cuba's health care facilities were concentrated in the cities. From then on, the country began to implement a new, single health system, free and universally accessible to its population, and $100 \%$ publicly funded.[7] In the early 1960s, the Faculty of Medicine was reopened at the University of Havana, and shortly after, medical education was extended to all provinces. Thereafter, the number of physicians, nurses, and other health care workers rapidly increased, expanding access to care throughout the country. By 1970, there were 53 hospitals in rural areas.[8]

The public health budget also provides training to physicians and addresses public health issues, including programs for health promotion and education. Several national programs were developed around maternal-child health, older adult health, sexually transmitted and other infections, as well as chronic conditions and prevention of toxic habits such as smoking and alcohol consumption. Since the early 1980s, primary health care was given a particular boost with the creation of the neighborhood-based family doctor-and-nurse program, complementing multispecialty community polyclinics, 
as well as secondary and tertiary care, to improve individual and population health outcomes.[8] Between 1960 and 2010, the transformation of Cuba's health system was accompanied by reductions in infant mortality, low birth weight rates, and infectious and parasitic disease mortality, as well as increases in life expectancy-to the extent that Cuba achieved health indicators similar to and in some cases better than those of the USA.[8]

Before 1959, Cuba relied heavily on imported medicines from other countries such as the United States-the USA being one of the world's largest manufacturers of medicines and medical devices.[3] Once the US embargo was imposed, drugs from the USA could no longer be exported to Cuba. In turn, no Cuban products such as medications, could be purchased from Cuba for US patients. The embargo was tightened twice in the 1990s, both times with international, extraterritorial implications. First, among other things, the Cuban Democracy Act passed by Congress in 1992 prohibited trade by Cuba with subsidiaries of US companies abroad, and then in 1996 the Cuban Liberty and Democratic Solidarity Act threatened to impose penalties on institutions and countries that invested in or partnered with Cuba. These policies had negative impacts on health and US-Cuba cooperation in medicine and medical research.[5,9]

Despite privations due to economic constraints, the Cuban health system has been widely recognized internationally for its practices and outcomes. Unfortunately, isolation from the USA has not allowed Cuban products to compete in the US domestic market or its significant contributions in the fields of medicine and biotechnology to be recognized in the United States. These contributions include effective vaccines against meningitis $B$ and hepatitis $\mathrm{B}$. While licensing agreements were negotiated with major pharmaceutical companies such as Glaxo-Smith-Kline, to explore bringing Cuban biotechnology in North America and Europe, they were never fully implemented.[10]

Government support for health care and medical research remains generous in Cuba. Health care was a major countrywide priority under then-President Fidel Castro, who also placed great emphasis on research and knowledge development. This is reflected in the fact that Cuba started biotech research and production as early as 1982. The world's first biotech company (Genentech) opened in the USA in 1976; Cuba's Center for Biological Research, producing both natural and recombinant interferons, opened in January 1982. While there were financial constraints, science was valued enough to receive the needed funds to stay current as biotechnology research expanded worldwide.

Today, Cuba's globally recognized BioCubaFarma Enterprise Group consists of 31 enterprises and 8 commercial companies with over 20,000 employees and 62 manufacturing facilities. BioCubaFarma enterprises produce 525 of the 849 medicines included in the Essential Drugs List of Cuba's Ministry of Public Health, has been granted over 800 sanitary registrations abroad and exports to 48 countries.[11]

Given its experience in biotechnology and drug development, Cuba is well equipped to participate in clinical trials within the FDA regulatory framework. In 2007, Cuba's National Clinical Trial Registry went live and four years later became the first WHO- accredited primary registry in the region. Cuban clinical trials adhere to international good clinical practice standards. Cuba completed 150 clinical trials between 1992 and May 2016, with increased approval of study protocols since 1996. Their first large-scale multicenter clinical trial was begun in 1996, involving 52 hospitals in testing recombinant streptokinase for treatment of acute myocardial infarction. After successful completion, the Cuban-developed drug was registered and is now sold in over 25 countries. As of May 2016, Cuba was conducting 30 clinical trials abroad in 18 countries.[12]

Bilateral cooperation in cancer research: the work of US and Cuban institutions $\mathrm{RPCl}$ was founded in 1898 under the vision of Dr Roswell Park. Dr Park, a practicing surgeon, held the view that cancer would become a leading cause of death, and thus was intent upon making RPCl the first institution in the world that focused entirely on cancer and cancer research. He believed in translational research as a means to bridge basic laboratory science, clinical cancer research and patient-population health.[13]

With the help of Dr Edward Butler, a grant was proposed to develop the first cancer research laboratory, originally called the New York State Pathological Laboratory of the University of Buffalo, the embryo of RPCI. In 1974, RPCI became the first $\mathrm{NCl}$-designated comprehensive cancer center. It also received accreditation through the Joint Commission on Accreditation of Healthcare Organizations and became a member of the National Comprehensive Cancer Network. With this affiliation, RPCI gained the ability to deliver the most promising, cutting-edge therapies through collaborations with other institutes around the USA.[13]

CIM was founded in Havana in January 1991 and its present venue inaugurated in 1994. The founding group had been working on cancer immunology since 1979 at the Cuban National Institute of Oncology and Radiobiology. Research on the role of epidermal growth factor (EGF) in cancer started in 1981, and Cuban authors published their first paper worldwide describing the presence of EGF receptors in human breast cancer in 1984.[14] CIM now operates four manufacturing facilities and has $>1100$ employees. It exports products to over 30 countries and has filed 750 patents abroad, including in the USA. CIM researchers have produced over 500 peer-reviewed scientific papers. In 1995, clinical trials began in Cuba to study CIM-developed CIMAvax-EGF, a cancer vaccine designed primarily for advanced stage non-small cell lung cancer (NSCLC) patients.[15] This vaccine targets the EGF that can drive growth of NSCLC and other cancers. After trials were completed successfully and CIMAvax-EGF was approved and registered by the Cuban regulatory authority, it has become available to Cuban patients in the public health system since 2011. [16] This novel vaccine led the way for collaboration between CIM and $\mathrm{RPCl}$.

Development of CIMAvax-EGF Vaccine The first phase I/II openlabel trial was conducted at the Medical-Surgical Research Center in Havana in 1995, involving ten patients with malignant tumors at various locations. The vaccine was further developed for NSCLC therapy, since a response due to overexpression of the EGF receptor (EGFR) was seen in primary NSCLC tumors.[17]

CIMAvax-EGF vaccine induces antibodies against EGF. Through EGF immune deprivation, the immune system is able to decrease circulating EGF and prevent binding of the ligand to EGFR, the 
EGF receptor. In turn, this disrupts proliferation of cancer cells. After vaccination, studies have shown inverse correlation between circulating EGF and antibody response.[16]

Currently, the vaccine has been tested in more than 5000 advanced NSCLC patients and has proven to be safe. During phase II studies, the vaccine was administered after first-line platinum-based doublet chemotherapy. The studies showed the vaccine was safe and produced anti-EGF antibodies. Patients that received the vaccine also showed a trend to increased survival, with those who reached an antibody response of $\geq 4000$ showing better survival.[17,18]

A phase III randomized trial evaluated the vaccine with best supportive care vs. best supportive care alone. This trial included all patients who had achieved stable disease, partial or complete response upon receiving first-line platinum-based doublet chemotherapy. The study included 270 participants in the vaccine group and 135 participants in the best supportive care group (control). Most common adverse events included mild or moderate injection site reactions along with fever, headache, malaise, chills and vomiting. The vaccine increased overall survival in the study population: average survival was 10.8 months for the vaccinated group vs. 8.9 months for the control group. The vaccinated group also showed a 5-year survival rate of $14.4 \%$ vs. $7.9 \%$ for controls. In the vaccine group (patients completing 4 vaccine doses) the median survival time was 12.4 months $(95 \% \mathrm{Cl}, 10.42-14.45)$ vs. 9.4 months $(95 \% \mathrm{Cl}, 7.53-11.33)$ in the control group (composed of patients surviving for at least 6 weeks). Five-year survival was $16.6 \%$ for patients who received 4 vaccine doses versus $6.2 \%$ for unvaccinated patients.[19]

Prolonged use of the vaccine was found to be safe in NSCLC patients. Repeated vaccinations were shown necessary to maintain low levels of circulating EGF and a high anti-EGF antibody response. Patients with high EGF serum levels at baseline had better survival (14.7 months) than unvaccinated patients with similar EGF serum concentrations (8.6 months). Interestingly, 5-year survival was $23 \%$ for vaccinated patients with high EGF serum levels at baseline whereas no patients in the control group were alive by that time. $[19,20]$

After completion of the phase III trial, a phase IV trial began to evaluate administration of the vaccine in a primary care setting. Vaccine safety was reconfirmed, and the primary care setting allowed for better access to the vaccine and increased compliance with administration. Clinical trials are now running to confirm EGF as a predictive biomarker for the vaccine's efficacy.[20]

Cancer research collaboration: external conditions, motivation, process, results New collaboration between the USA and Cuba facilitated sharing resources that otherwise would not have been available to institutions in countries that were previously isolated from each other. While there is always room for mutual learning, working together more often creates new knowledge that can benefit both countries' populations.

Additionally, Cuba's closed-loop approach to medical research closely aligns with Roswell Park's mission. That is, rather than focusing on scientific results alone, both have adopted the approach that their medical investigations should bring results that translate into development and manufacture of new products that meet population health needs. Success in exporting these new products closes the loop, providing a monetary incentive and sense of responsibility to continue research. This closedloop approach, already in place in Cuba, motivates scientists to develop more innovative and advanced products.[21]

In 2011, scientists from CIM visited RPCI, taking the first steps toward collaboration in drug development. After many discussions at international conferences, it took two years for an agreement to be drafted providing for CIM's cancer vaccines, including CIMAvax-EGF, to be tested in US patients at RPCI. This was the start of a collaboration that holds the promise of bringing these novel therapies to US physicians and their patients.

In 2013, $\mathrm{RPCl}$ received an OFAC license for clinical trials in the USA of two CIM cancer vaccines and three of its immunomodulatory drugs. Within months, the necessary protocols and legal agreements were under development between CIM and RPCI. During New York state's trade mission to Cuba in April 2015, $\mathrm{RPCl}$ and CIM signed the formal agreement to work together and agreed upon the importance of such collaboration across borders to further test CIM vaccines. A year later, an investigational new drug application to the US FDA was approved for the first phase I trial of CIMAvax-EGF with the checkpoint inhibitor, nivolumab (Opdivo), in patients with late-stage, advanced NSCLC.

Bilateral collaboration in clinical trials $\mathrm{RPCl}$ opened the first clinical trial testing the CIMAvax-EGF vaccine combined with nivolumab in late 2016. The estimated enrollment for this phase I/ II trial is 136 participants. Currently the estimated study completion date is June 2021. The trial's primary objectives are to evaluate the safety of the combination of the vaccine and nivolumab, determine overall survival, and assess antibody titers and EGF levels.[22]

Thousands of requests from around the world were received to participate in the trial. An inquiry form was issued by $\mathrm{RPCl}$ to determine eligibility for enrollment. Questions included were, among others, the patient's diagnosis, prior therapies and willingness to participate in the trial. If the patient seemed eligible according to basic disease characteristics and history of treatment, they were individually contacted about possible enrollment. A total of 959 potentially eligible participants, families, friends, health care providers and caregivers were given detailed information about the trial between October 2016 and November 2017. Inquires came from 47 US states and over 48 countries. More than half were from family members and over a quarter were self-referrals.

While eligibility and the number of patients who can enroll in a clinical trial remain tightly controlled, the cancer community has shown interest in the new therapies available through the $\mathrm{RPCl}-\mathrm{CIM}$ collaboration. $\mathrm{RPCl}$ expects the same positive feedback from the community when the next US clinical trial opens with another therapy developed at CIM, nimotuzumab, a monoclonal antibody that recognizes EGFR, approved since 2005 for use in Cuba's National Health System.[12] Thus, the opening of the phase I/II CIMAvax-EGF vaccine clinical trial at Roswell Park is only the beginning, and should lead to FDA approval for future general use and sale of such products developed in Cuba. 


\section{ANALYSIS: OPPORTUNITIES AND CHALLENGES}

The thaw in relations between the USA and Cuba during the Obama administration expanded opportunities for researchers to network and form collaborations, but those opportunities are limited and subject to reversal.

In October 2016, an executive order by President Obama prompted OFAC regulatory changes that enable engagement with Cuba on joint medical research projects-both commercial and noncommercial-under general license. These include the opportunity to obtain approval from the FDA for pharmaceuticals originating and developed in Cuba. The general license also allows US grants to be awarded to Cuban nationals engaging in scientific research.[23,24]

While a specific OFAC license has been issued for the collaboration between $\mathrm{RPCl}$ and $\mathrm{CIM}$, political hurdles remain. Under OFAC policy, the license provides approval for only preclinical and clinical research using products developed in Cuba. While OFAC regulations under the Obama presidency opened the way for Cuban-origin products to go through the entire regulatory process, receive approval if safe and effective, and be marketed, it is unclear as of this writing if this ruling will hold up in the current climate - a clear disincentive for US companies to invest in trials or become involved in such collaborations, no matter how potentially beneficial to US patients.[24]

Such uncertainties plague the future of US-Cuba collaboration in cancer research under the change in US administration. While under the Obama administration, the two countries were able to advance in establishing scientific links, it is uncertain whether the Trump administration will go along the same lines or will erect barriers to those ties.

However, even in these circumstances, joint efforts by CIM and $\mathrm{RPCl}$ bring new hope to lung cancer patients by offering them the results of efforts to obtain new and more effective therapies. The OFAC license for CIM's and RPCl's joint work paves the way for other academic institutions and companies to engage in bilateral collaboration to develop new therapies, also needed to limit or eliminate toxicity currently seen with other cancer treatments. These new agents may also lead to more cost-effective care for cancer patients and for those suffering other life-threatening diseases.

Because of this multiyear effort, greater collaboration in research is also expected to accelerate development of new agents, both those developed at $\mathrm{CIM}$ and at RPCI, with the goal of benefiting patients with cancer in both countries. These hold the promise of obtaining therapies that would not otherwise be available to US patients, and future discoveries will benefit from cooperation, each partner providing assistance to the other to complement areas of strength and fill the gaps in each other's knowledge. In the best interests of both countries and populations, these new channels of collaboration should be preserved.

\section{ACKNOWLEDGMENTS}

We thank Drs Agustín Lage, Kalet Leon and Tania Crombet, and all CIM faculty and staff for their collaboration, support and friendship. $-1 /$ -

\section{REFERENCES}

1. Office of the Historian, B.o.P.A., U.S. Department of State. A Guide to the USA's History of Recognition, Diplomatic, and Consular Relations, by Country, since 1776: Cuba [Internet].Washington, D.C.: U.S. Department of State; c2018 [cited 2018 Jan 15]; [about 2 screens]. Available from: https://history.state.gov/countries/cuba

2. United States International Trade Commission. Overview of Cuban Imports of Goods and Services and Effects of U.S. Restrictions. Washington, D.C.: U.S.I.T. Commission; 2016 Mar. 437 p.

3. Dalton R. Scientists strive to boost US-Cuban collaboration. Nature News. 2009 Jul 22:460:447.

4. New York State [Internet]. New York: New York State; c2018. Governor Cuomo's Trade Mission to Cuba Helps Connect New York Businesses to New Opportunities; 2015 Apr 22 [cited 2018 Jan 15]; [about 6 screens]. Available from: https://www .governor.ny.gov/news/governor-cuomos-trade -mission-cuba-helps-connect-new-york-business es-new-opportunities

5. U.S Department of Treasury. Cuban Liberty and Democratic Solidarity (Libertad) Act of 1996 (Codified in Title 22, Sections 6021-6091 of the U.S. Code) [Internet]. Washington. D.C.: U.S Department of Treasury; 1996 Mar [cited 2018 Jan 15]. 42 p. Available from: https://www.trea sury.gov/resource-center/sanctions/Documents/ libertad.pdf

6. U.S. Embassy in Cuba [Internet]. Washington, D.C.: U.S. Department of State; c2018 [cited 2018 Jan 15]. Available from: https:// cu.usembassy.gov/visas/

7. Pan American Health Organization. Cuba, Profile of the Health Services System, D.o.H.S.a.S.D. Program on Organization and Management of Health Systems and Services. Washington, D.C.:
Pan American Health Organization; 1999 Jun 8.

8. Keck W, Reed G. The curious case of Cuba. Am J Public Health. 2012 Aug;102(8):e13-e22.

9. The American Public Health Association [Internet]. Washington, D.C: APHA; c2018. The impact of economic embargoes on population health and wellbeing; 1997 Jan 1 [cited 2018 Dec 17]; [about 3 screens]. Available from: https://www .apha.org/policies-and-advocacy/public-health-po licy-statements/policy-database/2014/07/30/09/32/ impact-of-economic-embargoes-on-populations -health-and-wellbeing

10. Evenson D. Cuba's Biotechnology Revolution. MEDICC Rev. 2007 Oct;9(1):8-10.

11. BIOCUBAFARMA [Internet]. Havana: BIOCUBAFARMA; c2018 [cited 2018 Jan 16]. Available from: https://www.biocubafarma.cu/eng/. Spanish.

12. Gorry $\mathrm{C}$. The ABCs of clinical trials in Cuba. MEDICC Rev. 2016 Jul;18(3):9-14.

13. Roswell Park Cancer Institute [Internet]. New York: Roswell Park Institute; c2018. About Us; [cited 2016 Dec 6]. Available from: https://www.roswellpark.org/about-us

14. Pérez R, Pascual M, Macías A, Lage A. Epidermal growth factor receptors in human breast cancer. Breast Cancer Res Treat. 1984;4(3):189-93.

15. Rodríguez PC,Rodríguez G, González G, Lage A. Clinical development and perspectives of $\mathrm{Cl}$ MAvax EGF, Cuban vaccine for non-small-cell lung cancer therapy. MEDICC Rev. 2010 Winter;12(1):17-23.

16. Crombet Ramos T, Rodríguez PC, Neninger Vinageras E, García Verdecia B, Lage Dávila A. CIMAvax EGF (EGF-P64K) vaccine for the treatment of non-small-cell lung cancer. Expert Rev Vaccines. 2015;14(10):1303-11.
17. García B, Neninger E, de la Torre A, Leonard I, Martínez R, Viada $C$, et al. Effective inhibition of the epidermal growth factor/epidermal growth factor receptor binding by anti-epidermal growth factor antibodies is related to better survival in advanced non-small-cell lung cancer patients treated with the epidermal growth factor cancer vaccine. Clin Cancer Res. 2008 Feb 1;14(3):840-6.

18. Neninger Vinageras $E$, de la Torre A, Osorio Rodríguez M, Catalá Ferrer M, Bravo I, Mendoa del Pino M, et al. Phase II randomized controlled trial of an epidermal growth factor vaccine in advanced non-small-cell lung cancer. J Clin Oncol. 2008 Mar 20;26(9):1452-8.

19. Rodríguez PC, Popa X, Martínez O, Mendoza S, Santiesteban E, Crespo T, et al. A phase III clinical trial of the epidermal growth factor vaccine CIMAvax-EGF as switch maintenance therapy in advanced non-small cell lung cancer patients. Clin Cancer Res. 2016 Aug 1;22(15):3782-90.

20. Saavedra D, Crombet T. CIMAvax-EGF: A New Therapeutic Vaccine for Advanced Non-Small Cell Lung Cancer Patients. Front Immunol. 2017 Mar 13;8:269.

21. Lage A. Connecting science to population health: the "closed loop" approach. MEDICC Rev. 2007 Oct;9(1):48.

22. ClinicalTrials.gov [Internet]. Washington, D.C.: U.S. National Library of Medicine; c2018. CIMAvax vaccine and Nivolumab in treating patients with stage IIIB-IV non-small cell lung cancer; 2016 Nov 4 [cited 2017 Jul 15]; [updated 2018 Feb]. Available from: https://clinicaltrials.gov/ct2/ show/NCT02955290

23. Lee K. A small boat in a large uncharted ocean: case study in Cuban-American collaboration 
in cancer immunotherapy. In: $12^{\text {th }}$ International Workshop IMMUNOTHERAPY 2016: Mapping the Road for a Long Lasting Immune-Mediated Control of Cancer; 2016 Oct 17-21; Havana, Cuba. Havana. Havana: Molecular Immunology Center (CU); 2016 Oct 21.

24. Foreign Assets Control Office. 31 CFR Part 515 Cuban Assets Control Regulations. Federal Register . 2017 Nov 9;82(216):51998-2004.

\section{THE AUTHORS}

Rachel Evans, doctoral candidate in cancer sciences at the State University of New York at Buffalo, with a master's degree in pharma- ceutical sciences. Clinical research associate, Department of Clinical Research Services, Roswell Park Cancer Institute (RPCI), Buffalo, USA.

Mary Reid, nurse and epidemiologist. Professor of Oncology, Department of Medicine, and director, Cancer Screening and Survivorship, $\mathrm{RPCI}$, Buffalo, USA.

Brahm Segal, physician specializing in infectious diseases. Professor of oncology, chief of infectious diseases and member, Department of Immunology, RPCI, Buffalo, USA.
Scott I. Abrams, microbiologist and immunologist. Professor of oncology and member, Department of Immunology, RPCI, Buffalo, USA.

Kelvin Lee (Corresponding author: kelvin .Lee@RoswellPark.org), internist and medical oncologist. Chair, Department of Immunology $\mathrm{RPCI}$, Buffalo, USA.

Submitted: October 27, 2017

Approved for publication:April 3, 2018

Disclosures: None

\title{
13th International Workshop
} IMMUNOTHERAPY 2018

\author{
October 29-November 2, 2018 \\ Molecular Immunology Center, Havana, Cuba
}

\section{"Designing the next generations of cancer immunotherapies"}

\section{Main topics:}

- Translational clinical research: mechanisms of action and acquired resistance to current cancer immunotherapies

- Deciphering immunoregulatory circuits that impair immunotherapeutic efficacy in tumor microenvironments

- Design principles of effective immunotherapeutic combinations

- Protein engineering approaches to improve cancer treatment

- Novel cancer vaccines and adaptive cell therapies as strategies to increase numbers of nonexhausted immune effector cells in tumors

- Decrypting tumor biology to design more effective treatments

- In vivo imaging, computational biology and high throughput technologies to identify the right targets, the right effectors and the right tumor 